\title{
Effective in-service training design and delivery: evidence from an integrative literature review
}

\author{
Julia Bluestone ${ }^{1 *}$, Peter Johnson $^{1 \dagger}$, Judith Fullerton ${ }^{2}$, Catherine Carr ${ }^{1 \dagger}$, Jessica Alderman ${ }^{3}$ and James BonTempo ${ }^{1}$
}

\begin{abstract}
Background: In-service training represents a significant financial investment for supporting continued competence of the health care workforce. An integrative review of the education and training literature was conducted to identify effective training approaches for health worker continuing professional education (CPE) and what evidence exists of outcomes derived from CPE.

Methods: A literature review was conducted from multiple databases including PubMed, the Cochrane Library and Cumulative Index to Nursing and Allied Health Literature (CINAHL) between May and June 2011. The initial review of titles and abstracts produced 244 results. Articles selected for analysis after two quality reviews consisted of systematic reviews, randomized controlled trials (RCTs) and programme evaluations published in peer-reviewed journals from 2000 to 2011 in the English language. The articles analysed included 37 systematic reviews and 32 RCTs. The research questions focused on the evidence supporting educational techniques, frequency, setting and media used to deliver instruction for continuing health professional education.

Results: The evidence suggests the use of multiple techniques that allow for interaction and enable learners to process and apply information. Case-based learning, clinical simulations, practice and feedback are identified as effective educational techniques. Didactic techniques that involve passive instruction, such as reading or lecture, have been found to have little or no impact on learning outcomes. Repetitive interventions, rather than single interventions, were shown to be superior for learning outcomes. Settings similar to the workplace improved skill acquisition and performance. Computer-based learning can be equally or more effective than live instruction and more cost efficient if effective techniques are used. Effective techniques can lead to improvements in knowledge and skill outcomes and clinical practice behaviours, but there is less evidence directly linking CPE to improved clinical outcomes. Very limited quality data are available from low- to middle-income countries.
\end{abstract}

Conclusions: Educational techniques are critical to learning outcomes. Targeted, repetitive interventions can result in better learning outcomes. Setting should be selected to support relevant and realistic practice and increase efficiency. Media should be selected based on the potential to support effective educational techniques and efficiency of instruction. CPE can lead to improved learning outcomes if effective techniques are used. Limited data indicate that there may also be an effect on improving clinical practice behaviours. The research agenda calls for well-constructed evaluations of culturally appropriate combinations of technique, setting, frequency and media, developed for and tested among all levels of health workers in low- and middle-income countries.

Keywords: In-service training, Continuing professional education, Continuing medical education, Continuing professional development

\footnotetext{
* Correspondence: julia.bluestone@jhpiego.org

${ }^{\dagger}$ Equal contributors

1Jhpiego Corporation, 1615 Thames Street, Baltimore, MD 21231, USA

Full list of author information is available at the end of the article
}

\section{Biomed Central}

(c) 2013 Bluestone et al.; licensee BioMed Central Ltd. This is an Open Access article distributed under the terms of the Creative Commons Attribution License (http://creativecommons.org/licenses/by/2.0), which permits unrestricted use, distribution, and reproduction in any medium, provided the original work is properly cited. 


\section{Background}

The need to increase the effectiveness and efficiency of both pre-service education and continuing professional education (CPE) (in-service training) for the health workforce has never been greater. Decreasing global resources and a pervasive critical shortage of skilled health workers are paralleled by an explosion in the increase of and access to information. Universities and educational institutions are rapidly integrating different approaches for learning that move beyond the classroom [1]. The opportunities exist both in initial health professional education and $\mathrm{CPE}$ to expand education and training approaches beyond classroom-based settings.

An integrative review was designed to identify and review the evidence addressing best practices in the design and delivery of in-service training interventions. The use of an integrative review expands the variety of research designs that can be incorporated within a review's inclusion criteria and allows the incorporation of both qualitative and quantitative information [2]. Five questions were formulated based on a conceptual model of CPE developed by the Johns Hopkins University Evidence-Based Practice Center (JHU EPC) for an earlier systematic review of continuing medical education (CME) [3]. We asked whether: 1. particular educational techniques, 2. frequency of instruction (single or repetitive), 3. setting where instruction occurs, or 4. media used to deliver the instruction make a difference in learning outcomes; and, 5. if there was any evidence regarding the desired outcomes, such as improvements in knowledge, skills or changes in clinical practice behaviours, which could be derived from CPE, using any mixture of technique, media or frequency.

\section{Methods}

\section{Inclusion/exclusion criteria}

Articles were included in this review if they addressed any type of health worker pre-service or CPE event, and included an analysis of the short-term evaluation and/or assessment of the longer-term outcomes of the training. We included only those articles published in English language literature. These criteria gave priority to articles that used higher-order research methods, specifically meta-analyses or systematic reviews and evaluations that employed experimental designs. Articles excluded from analysis were observational studies, qualitative studies, editorial commentary, letters and book chapters.

\section{Search strategy}

A research assistant searched the electronic, peer-reviewed literature between May and June 2011. The search was conducted on studies published in the English language from 2000 to 2011. Multiple databases including PubMed, the Cochrane Library and Cumulative Index to Nursing and Allied Health Literature (CINAHL) were utilized in the search. Medical subject headings (MeSH) and key search terms are presented below in Table 1.

\section{Study type, quality assessment and grade}

An initial review of titles and abstracts produced 244 results. We identified the strongest studies available, using a range of criteria tailored to the review methodology. Initial selection criteria were developed by a panel of experts. Grading and inclusion criteria are presented in Table 2. The grading criteria were adapted from the Oxford Centre for Evidence-Based Medicine (OCEMB) levels of evidence model [4]. Grading of studies included within systematic reviews was reported by authors of those reviews and was not further assessed in this integrative review. Therefore, reference to quality of studies in our report refers to those a priori judgments. Only tier 1 articles (grades 1 and 2) were included in our analysis.

After prioritization of the articles, 163 tier 1 articles were assessed by a senior public health professional to determine topical relevance, study type and grade. A total of 61 tier 1 studies were selected to be included in the analysis following this second review. An additional hand search of the reference lists cited in published studies was conducted for topics that were underrepresented, specifically on the frequency and setting of educational activities. This search added eight articles for a total of 69 studies, including 37 systematic reviews and 32 randomized controlled trials (RCTs), see inclusion process for articles included in analysis, Figure 1.

A data extraction spreadsheet was developed, following the model offered in the Best Evidence in Medical Education (BEME) group series [5] and the conceptual model and definition of terms offered by Marinopoulos et al. in the JHU EPC earlier review of CME [3]. Categorization decisions were necessary in cases when the use of terminology was inconsistent with the Marinopoulos et al. definitions of terms for CPE [3]. For example, an article that analysed 'distance learning' as a technique and used the computer as the medium to deliver an interactive elearning course was coded and categorized as an 'interactive' technique delivered via 'computer' as the medium of instruction. See illustration of categorization terminology in panels A, B, and C, Figure 2, for an illustration of how terminology was used to categorize and organize articles for analysis.

\section{Results}

Selected articles that best represent common findings and outcomes (effects) of CPE are discussed in the results and discussion sections; the related tables present all the articles analysed and categorized for that topic, and each article is included only once. Relevant information obtained from educational psychology literature is referenced in the discussion. 
Table 1 Medical subject headings (MeSH) and key search terms

\begin{tabular}{lll}
\hline Group-based education & Asynchronous distance learning & Nursing education \\
Facility-based education & Synchronous distance learning & Medical education \\
On-the-job education & Online learning & Teaching methods \\
Group-based training & Distance learning & Health care professionals \\
Facility-based training & Continuing medical education & Education methods \\
On-the-job training & Continuing nursing education & Continuing education methods \\
Point-of-care training & & Nursing education methods \\
Mobile technologies & & Medical education methods \\
\hline
\end{tabular}

\section{Techniques}

The articles or studies that specifically addressed educational techniques are summarized in Table 3 . Technique refers to the educational methods used in the instruction. Technique descriptions are based on the Marinopoulos et al. definitions of terms [6] and reflect the approaches defined in the articles analysed.

\section{Case-based: use of created or actual clinical cases that present materials and questions}

Though case-based learning was not specifically compared with other techniques in the literature reviewed, it was often noted as a method in articles that discussed interactive techniques. Case-based learning was also noted as a technique used for computer-delivered CPE courses. Triola et al. compared types of media utilized for case-based learning and found positive learning outcomes both with the use of a live standardized patient and a computer-based virtual patient [7].

\section{Didactic/lecture: presenting knowledge content; facilitator determines content, organization and pace}

Lecture was often referred to in the literature as traditional instruction, lecture-based or didactic teaching. Didactic instruction was not found to be an effective educational technique compared with other methods. Two studies $[8,9]$ found no statistical difference in learning outcomes, and three studies found didactic to be less effective than other techniques [10-12]. Reynolds et al. compared didactic instruction with simulation. The study was limited by small sample size $(n=50)$, but still demonstrated that the simulation group had a significantly higher mean post-test score $(P<0.01)$ and overall higher learner satisfaction [12].

Several systemic reviews that compared didactic instruction to a wide variety of teaching approaches also identified didactic instruction as a less effective educational technique [13-15].

\section{Feedback: providing information to the learner about performance}

Multiple articles identified feedback as important for outcomes [16-18]. Herbert et al. compared individualized feedback in the form of a graphic (a prescribing portrait based on personal history of drug-prescribing practices) to small group discussion of the same material and found that both the feedback and the live, interactive session were somewhat effective at changing physician's prescribing behaviours [16]. The Issenberg et al. systematic review of simulation identified practice and feedback as key for effective skill development [17]. A Cochrane review of the evidence to support CPE suggested the importance of feedback and instructor interaction in improving learning outcomes [18].

\section{Games: competitive game with preset rules}

The use of games as an instructional technology was addressed in one rigorous systematic review. The authors found only a limited number of studies, which were of low

Table 2 Grading criteria

\begin{tabular}{lll}
\hline Design & Type of groups & Literature grade \\
\hline Meta-analysis or systematic review & NA & 1 \\
Experimental & Between subjects (experimental and control) & 2 \\
& Within subjects (crossover) & 2 \\
Quasi-experimental & Non-equivalent control group & 3 \\
Pre-experimental & Repeated measures & 3 \\
& Comparison group & 4 \\
\hline
\end{tabular}




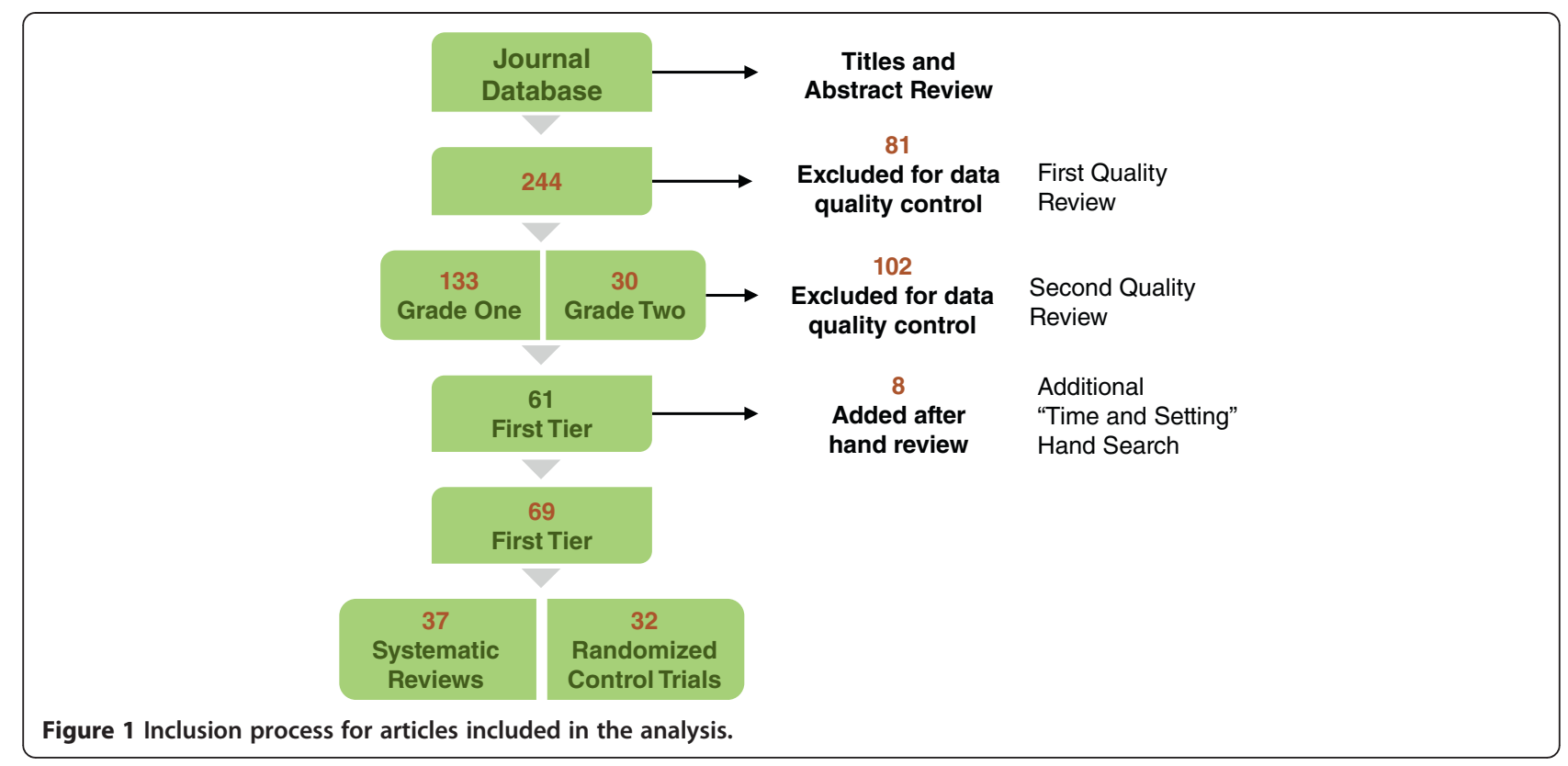

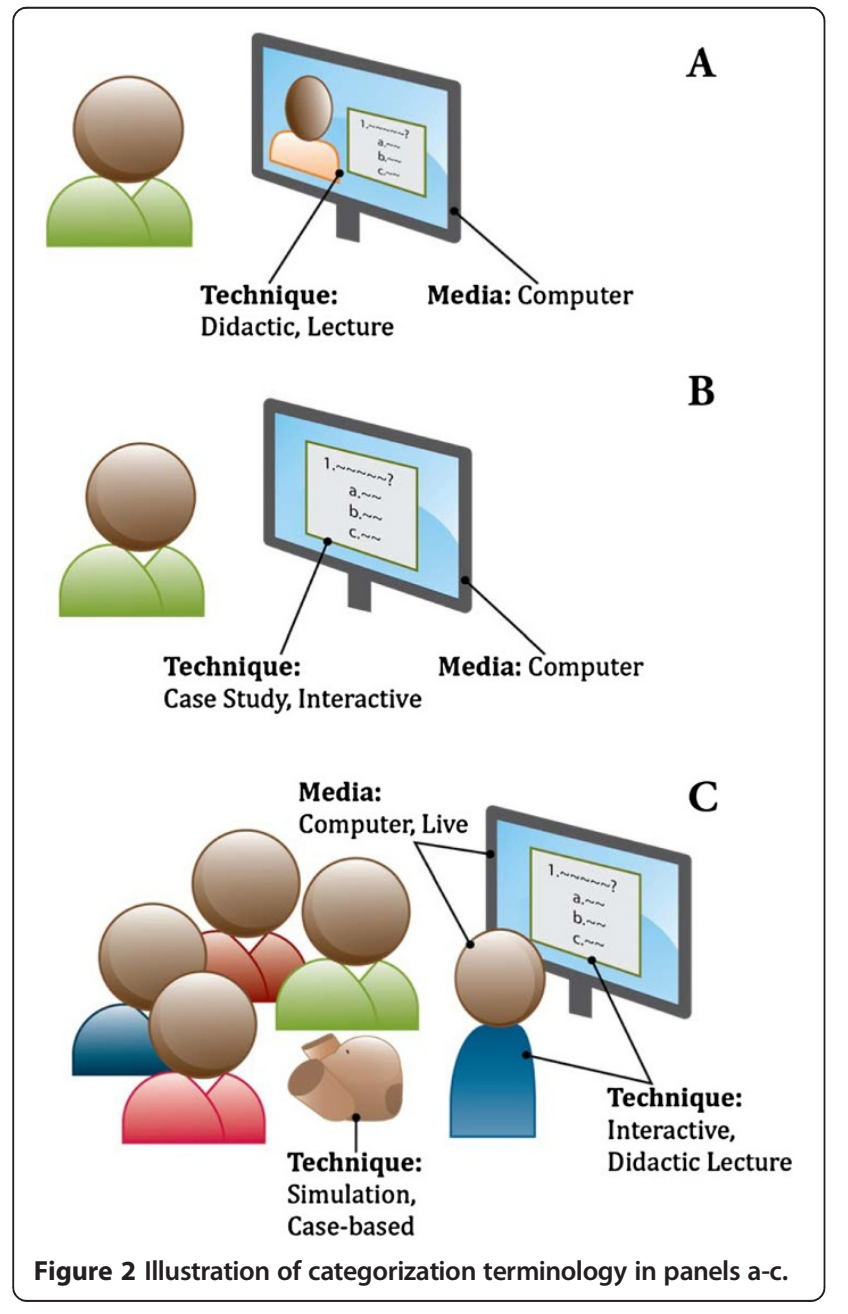

to moderate methodological quality and offered inconsistent results. Three of the five RCTs included in the review suggested that educational games could have a positive effect on increasing medical student knowledge and that they include interaction and allow for feedback [19].

\section{Interactive: provide for interaction between the learner and facilitator}

Five articles specifically compared interactive CPE to other educational techniques. De Lorenzo and Abbot found interactive techniques to be moderately superior for knowledge outcomes than didactic lecture [10]. Two other studies found interactive techniques were more effective when feedback from chart audits was added to the intervention $[16,20]$.

Three systematic reviews and one meta-analysis specifically noted the importance of learner interactivity or engagement in learning in achieving positive learning outcomes [21-24] (refer to summary of articles focused on outcomes).

Point-of-care (POC): information provided as needed, at the point of clinical care

Two articles and one systematic review specifically addressed point-of-care (POC) as a technique. The systematic review included three studies and concluded that while the findings were weak, they did indicate that POC led to improved knowledge and confidence [25]. In an examination of media, Leung et al. determined that handheld devices were more effective than print-based, POC support, although outcome measures were selfreported behaviours [26]. You et al. found improved performance on a procedure among surgical residents who 


\section{Citation}

Aki E et al. 2010 Study design

Systematic review: five articles reviewed to Mostly medical students determine the effectiveness of educational gaming on learning

Blaya J et al. 2010

Systematic review: 45 articles included for review, only three related to POC support,

included qualitative and quantitative data

Bruppacher $\mathrm{H}$ et al. 2010 Prospective, single-blinded $\mathrm{RCT}$ to determine if simulation or interactive techniques are better for teaching weaning a patient from anaesthesia

Anaesthesiology trainees, post-graduate year 4

I = 10, C = 10

Country: China

Prospective $\mathrm{RCT}$ to determine if simulation is more effective than didactic in obstetric emergency management

Residents and labour and delivery nurses

$\mathrm{I}=16, \mathrm{C}=16$

Country: USA

$\mathrm{RCT}$ to determine if the adult learning model improves student learning in terms of cognitive performance and perception of proficiency in military medic training

Army medic students $n=150, I=81, C=69$

Country: USA

\section{Intervention}

Key findings

Technique: educational games

Media: multiple

Frequency: NR

Technique: didactic vs POC

Media: computer-based vs live

Frequency: NR

Technique: simulation vs interactive

Media: live

Frequency: single

Intervention group received simulation-based training; control group received an interactive seminar.

Technique: simulation vs interactive

Media: live

Frequency: single

Intervention group received simulation-based raining; control group received an interactiv seminar.

Technique: interactive vs didactic

Media: live

Frequency: single

Intervention group emphasized the principles of adult learning including small group interactive approach, self-directed study, multimedia didactics and intensive integrated practice of psychomotor skills; control group received a traditional, lecture-based course.

Technique: simulation

Media: multiple

Frequency: single
Findings in three of the five RCTs suggested but did not confirm a positive effect of the games on medical students' knowledge.

POC findings: studies were weak but indicated knowledge improved and increased rapport in trusting personal judgment

The simulation group scored significantly higher than the seminar group at both post-test and retention test. Clinical decision-making/psychomotor skills can be acquired via simulation.

Simulation-trained teams had superior performance scores when tested in a labour and delivery drill. In an academic training programme, didactic and simulation-trained groups showed equal results on written test scores.

The adult learning model offered only a modest improvement in cognitive evaluation scores over traditional teaching. Additionally, students in the traditional teaching model assessed themselves as proficient more

frequently than instructors, whereas instructor and student perception of proficiency were more closely matched in the adult learning model.

Inconclusive evidence about the use of simulation due to a low number of studies. However, the use of simulation, as opposed However, the use of sim lation, as opposed to other education and training methods (motor skills laboratory sessions with task trainers, computer-based instruction and lecture classes), increased students' clinical skills in the majority of studies. 
Table 3 Summary of articles focused on techniques (Continued)

Herbert C et al. $2004 \quad$ RCT to assess the impact of individualized Physicians

feedback and live, interactive group

education on prescriptive practices

Issenberg S et al. 2005

Systematic review: 109 studies reviewed to determine the use of high-fidelity medical simulations that lead to mos effective learning
Technique: audit and feedback vs interactive Increase in prescribing preference for correct

plus audit and feedback vs interactive session drug class in module and "prescribing only vs nothing

$11=48$, audit and feedback only; Media: live $12=47$, interactive module only;

$13=49$, interactive plus audit

and feedback; $C=56$, nothing

4,394 charts reviewed

Frequency: single

Country: Canada

Health professionals

\section{Technique: simulation}

Media: multiple

Frequency: both single and multiple

Technique: simulation

Literature review: nine articles reviewed to Health professionals determine effectiveness of experiential (focused on simulations) learning

Media: multiple

Frequency: both single and multiple

echnique: audit and feedback plus

practitioners to determine if chart audits and feedback reminders after a CME event lead to better adherence to clinical guidelines

RCT to determine if peer-tutored, PBL is preferable to didactic-based instruction for teaching nursing ethics interactive vs interactive only

Media: live

General practitioners $n=122, I=61, C=6$

Chart audit of 2,344 consenting Frequency: single vs multiple patient charts

Country: Canada

Nursing students

I $=72, C=70$

Country: Taiwan
Intervention group and control group received the same CME intervention, a 2-hour live, interactive workshop. The intervention group also received six monthly follow-up visits from a nurse that included chart screening, audits and feedback, and a print-based checklist distribution and print summary of expert recommendations.

Technique: PBL vs didactic

Media: live

Frequency: single individual, group and evidence based

prescribing practices) group. Evidence-based educational interventions combining personalized prescribing feedback with interactive group discussion can lead to modest but meaningful changes in physician prescribing.

The weight of the best available evidence suggests that high-fidelity medical

simulations facilitate learning under the right conditions. These conditions include: providing feedback, repetitive practice, curriculum integration, range of difficulty, multiple learning strategies, capture clinical variation, controlled environment,

individualized learning, defined outcomes and simulator validity.

None of the studies showed conclusively that simulated learning improves patient outcome; however, evidence suggests human patient simulators to be advantageous over other modalities. They have been proven to be at least as effective as traditional teaching by didactic methods. Both human patient simulators (models) and computer-simulations may be effective.

This study demonstrated significantly improved adherence in the intervention group using chart audits vs CME alone. The magnitude of the difference observed between the two groups in absolute pre-post intervention change is consistent with previous studies on the effectiveness of chart prompting in preventive care. 
Table 3 Summary of articles focused on techniques (Continued)

McGaghie W et al. 2009ª Systematic review: nine of the JHU EPC systematic review articles reviewed to determine the effectiveness of simulation methods in medical education outside of CME

Merien A et al. 2010

Systematic review: eight articles reviewed to determine the effectiveness of team-based training for obstetric care

Murad MH et al. 2010

Systematic review: 59 articles (enrolled 8,011 learners) reviewed to determine effectiveness of self-directed learning

Perry M et al. 2011

Systematic review: six articles representin five studies were reviewed to determine the effect of educational interventions in primary dementia care

Reynolds A et al. 2010

RCT to compare students' knowledge using either simulation or didactic lecture

Midwifery students $\mathrm{I}=26, \mathrm{C}=24$

Country: Portugal
Intervention group received PBL technique; control group received didactic-based

instruction.

Technique: simulation

Media: multiple

Frequency: both single and multiple

Technique: team-based

Media: live

Frequency: NR

Technique: self-directed

Media: multiple

Frequency: NR

Technique: multiple

Media: multiple

Frequency: both single and multiple

Technique: simulation vs didactic

Media: live

Frequency: single

ntervention group received simulation-based training: control group received didactic

lectures with print visuals. ethics in situations in which there are personnel and resource constraints.

Due to a low number of studies, evidence on simulation methods is inconclusive. However, the direction of evidence points to the

effectiveness of simulation training, especially

for psychomotor and communication skills.

Data analysis revealed a highly significant

'dose-response' relationship among practice and achievement, with more practice

producing higher outcome gains.

Due to a low number of studies, evidence on teamwork training in simulation is inconclusive. However, introduction of multidisciplinary teamwork training with integrated acute obstetric training interventions in a simulation setting is potentially effective in the prevention of errors, thus improving patient safety in acute obstetric emergencies.

Moderate-quality evidence suggests that self-directed learning in health professions education is associated with moderate improvement in the knowledge domain compared with traditional teaching methods, and may be as effective in the skills and attitudes domains.

Interactive workshops and decision support systems led to increased detection rates. Evidence shows moderate improvements in knowledge and techniques that required active participation tended to improve detection rates.

A significantly higher short-term reinforcement of knowledge and greater learner satisfaction was obtained using simulation-based training compared to image-based lectures when teaching routine management of normal

deaching routine mand resolution of shoulder dystocia to midwives in training. 
Table 3 Summary of articles focused on techniques (Continued)

RCT to compare effectiveness of PBL vs didactic for management of menta health problems

Steadman R et al. 2006

$R C T$ to determine if simulation is better than PBL for teaching assessment and management skills

Systematic review: 11 articles reviewed to determine if skills acquired by

simulation-based training transfer to the operative setting

Werb S and Matear D 2004 Systematic review: three systematic reviews and nine original research articles reviewed to examine evide clinical teaching and faculty continuing education didactic for asthma management

\section{Physicians}

$=23, C=29$

Country: Canada

Young J and Ward J 2002

Randomized trial to determine the effect of self-directed (distance) learning on

knowledge, attitudes and practices related

to smoking cessation

Family physicians

$=26, C=27$

Country: Australia
Technique: PBL vs didactic

Media: live

Frequency: single

Intervention group received $\mathrm{PBL}$ technique control group received didactic-based instruction.

Technique: simulation vs PBL

Media: live

Frequency: single

Intervention group received simulation-based teaching; control group received PBL.

Technique: simulation

Media: multiple

Frequency: both single and multiple

Technique: PBL

Media: multiple

Frequency: both single and multiple

Technique: PBL vs didactic

Media: live

Frequency: single

ntervention group received PBL technique control group received didactic-based

instruction.

Technique: self-directed vs reading

Media: print

Frequency: single

Intervention group received a self-directed earning module; control group received guidelines only.
The study found that both PBL and didactic-based instruction were effective, but had no statistical difference. The PBL

programme appeared to be more effective than the lecture-based programme in improving performance, but received less favourable evaluations.

Simulation-based teaching was superior to PBL for the acquisition of critical assessment and management skills.

Due to limited quality and methodology and a lack of relevant studies, a weak conclusion can be made supporting the transfer of skills developed in simulation to the operative setting. Evidence from one study showed better performance for participants who received simulation-based training before undergoing patient-based assessment than their counterparts who did not receive previous simulation training.

PBL and evidence-based health care interventions were effective in increasing students' knowledge of medical topics and their ability to search, evaluate and appraise medical literature. Dental students in a PBL curriculum, emphasizing evidence-based practices, scored higher on the National Dentistry Boards, Part I, than students in traditional curricula.

There was no significant difference in knowledge gained or satisfaction with the facilitator between the PBL group and the lecture-based group. The PBL group rated the educational value higher than the didactic group.

Modest changes from baseline to post-test for both the distance learning group and self-directed group suggest a lack of significant evidence to support a distance or self-directed approach to address changes in practice. 
Table 3 Summary of articles focused on techniques (Continued)

Yuan $\mathrm{H}$ et al. $2008 \quad$ Systematic review: 10 studies reviewed to Nursing students determine the evidence to support PBL

Cluster RCT at 107 rural health facilities to Health professionals

determine if text-message reminders

would improve provider adherence to

national malaria treatment guidelines

119 health workers

Case-management practices

were assessed for 2,269 children

who needed treatment

I $=1,157, C=1,112$

Country: Kenya
Technique: PBL

Media: multiple

Frequency: both single and multiple

Technique: reminders

Media: mobile phone

Frequency: repetitive

Intervention group received repetitive text

messages over a 6-month period; control

group received nothing.

aJHU EPC systematic review. C Control, CME Continuing medical education, I Intervention, JHU EPC Johns Hopkins University Evidence-Based Practice Center, NR Not reported, PBL problem-based learning,

$P O C$ point-of-care, $R C T$ randomized controlled trial.

Inconclusive evidence to support PBL. While several studies showed increased reported self-confidence in ability to make decisions, and several showed increased skills in critical thinking questions from the PBL group, overall findings were inconclusive due to a lack of quality studies.

The use of mobile technology showed significant improvement in case management practice for paediatric malaria cases among physicians with repetitive text-message reminders compared to control group. 
received POC mentoring via a video using a mobile device, compared with those who received only didactic instruction [27].

\section{Problem-based learning (PBL): present a case, assign information-seeking tasks and answer questions about the case; can be facilitated or non-facilitated}

Four articles specifically compared problem-based learning (PBL) to other methods. One study identified PBL as slightly better [11], and two studies indicated it to be relatively equal to didactic instruction $[8,9]$. A systematic review of 10 studies on PBL reported inconclusive evidence to support the approach, although several studies reported increased critical thinking skills and confidence in making decisions [28].

\section{Reminders: provision of reminders}

The Zurovac et al. study conducted in Kenya found that using mobile devices for repetitive reminders resulted in significant improvement in health care provider's case management of paediatric malaria, and these gains were retained over a 6-month period [29]. Intention-to-treat analysis showed that correct management improved by 23.7\% (95\% confidence interval (CI) 7.6 to $40.0, P<0.01$ ) immediately after intervention and by $24.5 \%$ (95\% CI 8.1 to 41.0, $P<0.01) 6$ months later, compared with the control group [29]. Reminders were also noted as an effective technique by two of the systematic reviews $[13,14]$.

\section{Self-directed: completed independently by the learner based on learning needs}

This term was difficult to extract for analysis due to widely varying terminology. Some authors used the term 'distance learning', and some used it to define the medium of delivery, rather than technique. This analysis specifically discusses articles that were consistent with the description for self-directed learning, even if the authors used different terminology.

A recent systematic review identified that moderatequality evidence suggests a slight increase in knowledge domain compared with traditional teaching, but notes that this may be due to the increased exposure to content [30]. One RCT found modest improvements in knowledge using a self-directed approach, but noted it was less effective at impacting attitudes or readiness to change [31].

Multiple studies focused on use of the computer as the medium to deliver instruction and noted that self-directed instruction was equally (or more) effective as instructorled didactic or interactive instruction and potentially more efficient.

Simulation may include models, devices, standardized patients, virtual environments, social or clinical situations that simulate problems, events or conditions experienced in professional encounters [17]. Simulation was noted as an effective technique for promotion of learning outcomes across the systematic reviews, particularly for the development of psychomotor and clinical decision-making skills. The systematic reviews all highlighted inconclusive and weak methodology in the studies reviewed, but noted sufficient evidence existed to support simulation as useful for psychomotor and communication skill development [32-34] and to facilitate learning [35]. The systematic review by Lamb suggests that patient simulators, whether computer or anatomic models, are one of the more effective forms of simulations [36].

Outcomes of the four separate RCTs indicated simulation was better than the techniques to which they were compared, including interactive [37,38], didactic [12] and problem-based approaches [35]. A study by Daniels et al. found that although knowledge outcomes were similar between the interactive and simulation groups, the simulation team performance in a labour and delivery clinical drill was significantly higher for both shoulder dystocia (11.75 versus 6.88, $P<0.01)$ and eclampsia $(13.25$ versus $11.38, P=0.032)$ at 1 month post-intervention [38].

Simulation was also found to be useful for identifying additional learning gaps, such as a drill on the task of mixing magnesium sulfate for administration [39]. A systematic review focused on resuscitation training identified simulation as an effective technique, regardless of media or setting used to deliver it [40].

\section{Team-based: providing interventions for teams that provide care together}

Articles discussed here focused on the technique of providing training to co-workers engaged as learning teams. One systematic review of eight studies found that there is limited and inconclusive evidence to support team-based training [41]. Two of the articles reporting on the same CPE study did not identify any improvements in performance or knowledge acquisition with the addition of using a team-based approach $[39,42]$.

\section{Frequency}

This review included consideration of frequency, comparing single versus repetitive exposure. The findings regarding frequency are summarized in Table 4.

The three articles focused on frequency all support the use of repetitive interventions. These studies evaluated repetition using the Spaced Education platform (now called Qstream), an Internet-based medium that uses repeated questions and targeted feedback. The evidence from these three articles demonstrated that repetitive, time-spaced education exposures resulted in better knowledge outcomes, better retention and better clinical decisions compared with single interventions and live instruction [43-45].

The use of repetitive or multiple exposures is supported in other systematic reviews of the literature, as well as one 
Table 4 Summary of articles focused on frequency

\section{Citation}

design

RCT to determine if spacing principles

can improve acquisition

of medical knowledge

Intervention

Frequency: multiple vs single

residents in each cohort

Of 537 participants, $400(74 \%)$

completed the online staggered tests

and 515 (96\%) completed the

n-Service Examination

Cohort 1 = bolus, single intervention;

Cohort 2 = multiple, spaced

intervention

Country: USA and Canada

Kerfoot BP et al. 2009 RCT to determine if Spaced Education Urologists and urology residents is an effective form of CME
Completed by $71 \%$ of urologists and $83 \%$ of residents

Cohort $1=80$ urologists, 160 residents, completed by 196 Cohort $2=80$ urologists, 160 residents, completed by 182

Country: USA (March to July 2007)
Technique: self-directed

Media: Internet-based

Cohort 1 received bolus education of 96 study questions (June 2005); Cohort 2 received daily emails over 27 weeks (June to December 2005), each with one to two questions in spaced pattern. In November 2005, all participants completed the urology exam. Participants were randomized to five cohorts and completed a 32-item online test at staggered time points (1 to 14 weeks) after completion of Spaced Education.

Frequency: multiple vs single

Technique: self-directed

Media: Internet-based

A total of 160 urologists and 320 urology residents were randomized to one of two cohorts. Participants were stratified by training level (urologist in practice vs resident) and urology training year (residents only) and were block randomized (block size $=8$ ) to one of two cohorts. Participants in Cohort 1 received the 3-cycle ISE course on the HP CPGs, with 24 control items on the SIA CPGs in cycle 3.

Participants in Cohort 2 received the 3-cycle ISE course on SIA CPGs, with 24 control items on HP CPGs in cycle 3. The trial was structured in this manner to allow the topic-specific learning gains from the ISE courses to be identified in cycle 3. Since the 24 items are presented simultaneously to both cohorts in cycle 3 , the learning gains of physicians who had completed two cycles of the ISE

programme could be directly compared with those physicians who were presented with the material for the first time (controls).
Key findings

Conclusive evidence to support repetitive, spaced education in online learning, since residents in the spaced education cohort demonstrated significantly greater online test scores than those in the bolus cohort. The scores for the spaced cohort remained stable with no overtime, while test scores in the bolus cohort demonstrated a significant linear decrease.

Conclusive evidence to support the use of ISE programmes. Knowledge scores of ISE intervention were statistically significantly higher than those of the control bolus method. 
Table 4 Summary of articles focused on frequency (Continued)

Kerfoot BP et al. 2010 RCT to determine if Spaced Education Urology residents

can effect knowledge transfer and the

ability to make diagnostic decisions

Cohort 1 = 164; Cohort $2=194$

Country: USA (June 2007 to June 2008) Media: Internet-based

Transfer and retention of diagnostic skills between Spaced Education vs bolus, WBT

All residents were sent both spaced education and WBT, but the set of topics delivered by each method varied by cohort. Residents in

Cohort 1 received three cycles of spaced

education on prostate-testis (weeks 1 to 4,5 to

8 , and 13 to 16) and three WBT modules on

bladder-kidney (weeks 14 to 16). Residents in

Cohort 2 received three cycles of spaced

education on bladder-kidney (weeks 1 to 4, 5 to

8 , and 13 to 16) and three WBT modules on

prostate-testis (weeks 14 to 16). The spaced

education items were delivered each weekday

through emails containing one question/answer,

and the spaced education material was

distributed in three cycles or repetitions to take

advantage of the spacing effect. The WBT used

the identical content and delivery system, with

the questions aggregated into three

20-question modules delivered through

separate emails in week 14. The triat was

specifically structured to ensure thal was

given set of topics (bladder-kidney or

given set of topics (bladder-kidney or

prostate-testis) the only difference between
intervention cohorts was the spacing of content.
Conclusive evidence to support spaced, Spaced education demonstrated a statically significant increase in knowledge and long-term retention of knowledge compared with bolus web-based module that delivered the same content of

histopathology diagnostic skills. 
RCT conducted in Kenya that used repeated text reminders and resulted in a significant improvement in adherence to malaria treatment protocols [29].

\section{Setting}

Setting is the physical location within which the instruction occurs. We identified three articles that looked specifically at the training setting. The findings regarding setting are summarized in Table 5. Two of them stemmed from the same intervention. Crofts et al. specifically addressed the impact of setting and technique (team-based training) on knowledge acquisition and found no significant difference in the post-score based on the setting [42]. A systematic review of eight articles evaluating the effectiveness of team-based training for obstetric care did not find significant differences in learning outcomes between a simulation centre and a clinical setting [41].

Coomarasamy and Khan conducted a systematic review and compared classroom or stand-alone versus clinically integrated teaching for evidence-based medicine (EBM). Their review identified that classroom teaching improved knowledge, but not skills, attitudes or behaviour outcomes; whereas clinically integrated teaching improved all outcomes [46]. This finding was supported by the Hamilton systematic review of $\mathrm{CPE}$, which suggests that teaching in a clinical setting or simulation setting is more effective (Table 1), as well as the Raza et al. systematic review of 23 studies to evaluate stand-alone versus clinically integrated teaching. This review suggested that clinically integrated teaching improved skills, attitudes and behaviour, not just knowledge [18].

\section{Media}

Media refers to the means used to deliver the curriculum. The majority of RCTs compared self-paced or individual instruction delivered via computer versus live, group-based instruction. The findings regarding media are summarized in Table 6.

\section{Live versus computer-based}

Live instruction was found to be somewhat effective at improving knowledge, but less so for changing clinical practice behaviours. When comparing live to computerbased instruction, a frequent finding was that computerbased instruction led to either equal or slightly better knowledge performance on post-tests than live instruction. One of the few to identify a significant difference in outcomes, Harrington and Walker found the computer-based group outperformed the instructor-led group on the knowledge post-test and that participants in the computer-based group, on average, spent less time completing the training than participants in the instructor-led group [47].

Systematic reviews indicate that the evidence supports the use of computer-delivered instruction for knowledge and attitudes; however, insufficient evidence exists to support its use in the attempt to change practice behaviours. The Raza Cochrane systematic review identified 16 randomized trials that evaluated the effectiveness of Internet-based education used to deliver $\mathrm{CPE}$ to practicing health care professionals. Six studies showed a positive change in participants' knowledge, and three studies showed a change in practice in comparison with traditional formats [18]. One systematic review noted the importance of interactivity, independent of media, in achieving an impact on clinical practice behaviours [48].

\section{Mobile}

One article assessed the use of animations against audio instructions in cardiopulmonary resuscitation (CPR) using a mobile phone and found the group that had audiovisual animations performed better than the group that received live instruction over the phone in performing CPR; however, neither group was able to perform the psychomotor skill correctly [49]. Leung et al. found providing POC decision support via a mobile device resulted in slightly better self-reporting on outcome measures compared with print-based job aids, but that both the print and mobile groups showed improvements in use of evidence-based decision-making [26].

\section{Print}

The systematic review of print-based materials conducted by Farmer et al. did not find sufficient evidence to support the use of print media to change clinical practice behaviours [50]. A comparison of the use of print-based guidelines to a live, interactive workshop indicated that those who completed live instruction were slightly better able to identify patients at high risk of an asthma attack. However, neither intervention resulted in changed practice behaviours related to treatment plans [51].

Multiple systematic reviews caution against the use of print only media, concluding that live instruction is preferable to print only. Another consistent theme was support for the use of multimedia in CPE interventions.

\section{Outcomes}

Outcomes are the consequences of a training intervention. This literature review focuses on changes in knowledge, attitudes, psychomotor, clinical decision-making or communication skills, and effects on practice behaviours and clinical outcomes. All of the articles that focused on outcomes were systematic reviews of the literature and are summarized in Table 7.

The weight of the evidence across several studies indicated that CPE could effectively address knowledge outcomes, although several studies used weaker methodological approaches. Specifically, computer-based instruction was found to be equally or more effective than 


\section{Table 5 Summary of articles focused on setting}

\section{Citation} Study design

Coomarasamy A and Khan K 2004 Systematic review: 23 articles reviewed (link to the follow-up study, Raza A et al. 2009)

to determine the effect of stand-alone compared to clinically integrated teaching in EBM

Prospective RCT to explore if knowledge acquisition is influenced by training setting or teamwork training

Ellis D et al. 2008

Same study design as Crofts et al. 2007 Crofts et al. 2007
Same participants as

\section{Intervention}

Technique: $m$

ost-graduate physicians,

allied health professionals

Media: live

Frequency: both single and multiple

Senior doctors, junior and Technique: team-based vs interactive senior midwives

Total of 140 participants;

interdisciplinary teams of

four or six in four blocks

Country: UK

Media: live

\section{Frequency: single}

11 = 1-day interactive at hospital (no team-based training); $12=1$-day interactive at simulation centre

(no team-based training); $13=2$-day team training at hospital; $14=2$-day interactive in simulation centre

Main outcome measured by a 185 multiple-choice questionnaire completed 3 weeks before and 3 weeks after the training intervention.

Same intervention as Crofts et al. 2007

\section{Key findings}

Sufficient evidence to support the use of

clinically integrated teaching over stand-alone

education. While stand-alone teaching improved

knowledge, there were no improvements in

skills, attitudes or behaviours, whereas clinically

integrated teaching showed improvements in

knowledge, skills, attitude and behaviour.

Statistical evidence supported the use of live, multi-professional, obstetric emergency training to increase midwives' and doctors' knowledge of obstetric emergency management. However, neither the location of training either in a simulation centre or in local hospitals, nor the inclusion of teamwork training, made any significant difference to the acquisition of knowledge in obstetric emergencies.

Statistical evidence to support the use of live eclampsia training to increase providers' performance rate for completion of basic tasks. Neither the location (simulation centre or in local hospitals), nor the inclusion of teamwork training made any significant difference to the performance results for basic task completion. 
Table 6 Summary of articles focused on media used to deliver instruction

\begin{tabular}{|c|c|c|c|c|}
\hline Citation & Study design & Participants & Intervention & Key findings \\
\hline \multirow{3}{*}{$\begin{array}{l}\text { Augestad K and } \\
\text { Lindsetmo R } 2009\end{array}$} & \multirow{3}{*}{$\begin{array}{l}\text { Systematic review: } 51 \text { articles reviewed } \\
\text { to determine usefulness of } \\
\text { videoconferencing as a clinical and } \\
\text { educational tool }\end{array}$} & Surgeons & Media: video & \multirow{3}{*}{$\begin{array}{l}\text { Review discussed primarily observational data } \\
\text { on the use of videoconferencing for provision } \\
\text { of lecture, mentoring and POC support for } \\
\text { emergencies or trauma settings. Methodology } \\
\text { of studies is weak, but shows promise for } \\
\text { providing POC and mentoring to rural settings } \\
\text { from specialists in other geographical areas. }\end{array}$} \\
\hline & & \multirow{2}{*}{$\begin{array}{l}\text { Country: Norway and developed } \\
\text { countries }\end{array}$} & Technique: multiple & \\
\hline & & & Frequency: NR & \\
\hline \multirow[t]{4}{*}{ Bloomfield J et al. 2010} & \multirow{4}{*}{$\begin{array}{l}\text { RCT to test if the theory and skill of } \\
\text { handwashing can be taught more } \\
\text { effectively when taught using } \\
\text { computer-assisted learning compared } \\
\text { to conventional face-to-face teaching }\end{array}$} & Nursing students & Media: computer-based vs live & \multirow{4}{*}{$\begin{array}{l}\text { The computer-assisted learning module was } \\
\text { an effective strategy for teaching both theory } \\
\text { and practice of handwashing to nursing } \\
\text { students and was found to be at least as } \\
\text { effective as conventional, face-to-face teaching } \\
\text { methods. However, this finding must be } \\
\text { interpreted with caution in light of sample } \\
\text { size and attrition rates. }\end{array}$} \\
\hline & & $\mathrm{n}=242, \mathrm{I}=113, \mathrm{C}=118$ & Techniques: multiple & \\
\hline & & Country: UK & Frequency: single & \\
\hline & & & $\begin{array}{l}\text { Intervention group received theory via } \\
\text { computer-based module; control group via } \\
\text { instructor-led. The objectives and content } \\
\text { were the same, both groups included } \\
\text { practice opportunities. }\end{array}$ & \\
\hline \multirow[t]{5}{*}{ Bradley P et al. 2005} & \multirow{5}{*}{$\begin{array}{l}\text { Prospective RCT and qualitative } \\
\text { evaluation to compare self-directed, } \\
\text { computer-based learning to traditional, } \\
\text { live, interactive education techniques }\end{array}$} & Medical students & Technique: self-directed vs interactive & \multirow{5}{*}{$\begin{array}{l}\text { There were no differences in outcomes for the } \\
\text { computer-based group compared to the live, } \\
\text { interactive group in knowledge acquisition, } \\
\text { critical appraisal skills or attitudes toward EBM. } \\
\text { This trial and its accompanying qualitative } \\
\text { evaluation suggest that self-directed, } \\
\text { computer-assisted learning may be an } \\
\text { alternative format for teaching EBM. }\end{array}$} \\
\hline & & $I=85, C=90$ & & \\
\hline & & Country: Norway & Media: computer-based vs live & \\
\hline & & & Frequency: single & \\
\hline & & & $\begin{array}{l}\text { Intervention group received self-directed, } \\
\text { computer-based modules on EBM; control } \\
\text { group received live, interactive sessions. }\end{array}$ & \\
\hline \multirow[t]{4}{*}{ Choa et al. 2008} & \multirow{4}{*}{$\begin{array}{l}\text { Single-blinded, cluster randomized trial } \\
\text { to compare the effectiveness of } \\
\text { audiovisual animated CPR instruction } \\
\text { with audio, dispatcher-assisted } \\
\text { instruction in participants with no } \\
\text { previous CPR training; both via mobile } \\
\text { phones }\end{array}$} & $\begin{array}{l}\text { Allied health professionals, } \\
\text { hospital employees }\end{array}$ & $\begin{array}{l}\text { Media: mobile, audiovisual animation vs audio } \\
\text { instructions from live dispatcher }\end{array}$ & \multirow{4}{*}{$\begin{array}{l}\text { Audiovisual animated CPR instruction via } \\
\text { mobile phone resulted in better scores in } \\
\text { checklist assessment and time interval } \\
\text { compliance in participants without CPR skill } \\
\text { compared to those who received CPR } \\
\text { instructions from a dispatcher. However, the } \\
\text { accuracy of important psychomotor skill } \\
\text { measures was unsatisfactory in both groups. }\end{array}$} \\
\hline & & $I=44, C=41$ & Technique: POC & \\
\hline & & Country: Korea & Frequency: single & \\
\hline & & & $\begin{array}{l}\text { Intervention group used mobile phone } \\
\text { application with audiovisual animation } \\
\text { instructions for CPR; control group received } \\
\text { audio guidance from a live dispatcher. }\end{array}$ & \\
\hline \multirow[t]{4}{*}{ Chui S et al. 2009} & \multirow{4}{*}{$\begin{array}{l}\text { Experimental research design with two } \\
\text { groups, one pre-test and two post-tests, } \\
\text { to determine the effectiveness of } \\
\text { computer-based interactive instruction } \\
\text { vs video didactic instruction }\end{array}$} & Nurses & Media: computer-based vs video & \multirow{4}{*}{$\begin{array}{l}\text { Interactive, computer-assisted instruction } \\
\text { increased student assessment correctness } \\
\text { compared to video didactic instruction for } \\
\text { in-service neurological nursing education } \\
\text { after statistical adjustments for length of } \\
\text { experience. }\end{array}$} \\
\hline & & $I=44, C=40$ & Technique: self-directed interactive vs didactic & \\
\hline & & Country: Taiwan & Frequency: single & \\
\hline & & & $\begin{array}{l}\text { Intervention group received computer-based, } \\
\text { interactive educational module; control group } \\
\text { watched a video of a lecture. }\end{array}$ & \\
\hline
\end{tabular}

Media: computer-based vs live

Intervention group received self-directed, computer-based modules on EBM: contro group received live, interactive sessions.

Media: mobile, audiovisual animation vs audio

Frequency: single

ntervention group used mobile phone application with audiovisual animation

Media: computer-based vs video

Frequency: single

watched a video of a lecture. 
Table 6 Summary of articles focused on media used to deliver instruction (Continued)

Curran V and Fleet L 2005 Systematic review to evaluate the nature and characteristics of the web-based CME, based on Kirkpatrick levels of evaluation; 86 studies were identified, majority were descriptive

Farmer A et al. 2008

Fordis M et al. 2005 Systematic review: 23 studies reviewed to determine the usefulness of print-based materials in practice behaviours or clinical practice outcomes

$R C T$ to determine if Internet-based CME can produce changes comparable to those produced via live, small group, interactive CME with respect to physician knowledge and behaviours that have an impact on patient care

Health care professionals

Physicians

$n=97,1=49$, randomly assigned Internet-based over 2 weeks;

$=44$, single, live, interactive session; $C 2=18$, from same sites received nothing

Country: USA

Post-graduate medical trainees, interns

effectiveness of a clinically integrated e-learning course for teaching basic BM among post-graduate med trainees compared to a traditional ecture-based course of equivalent content

I $=88, C=72$

Country: UK

\section{Nurses}

cT to determine effectiveness of computer-based training compared with the traditional, instructor-led format

Country: USA
Media: print

Technique: didactic

Frequency: single

\section{Media: Internet}

nique: multiple

Frequency: both single and multiple Frequency: single

ntervention group received Internet-based modules over 2 weeks; one control group received a live, interactive session and the

Media: Internet vs live

Frequency: single

Intervention group received clinical integrated e-learning course on EBM; control group received live, didactic-based course.

Media: computer-based vs live Technique: didactic vs self-directed Frequency: single

Intervention group received self-directed, computer-based instruction; control group received instructor-led, live instruction. Both groups had the same objectives and content. other control group received nothing.

Techniques: multiple

Inconclusive evidence to identify the most seb-based CME due to a lack of studies focusing on performance change. Findings suggest web-based CME is effective in enhancing knowledge and attitudes. Several studies suggest interactive CME that requires participant activity and the chance to practice skills can effect changes in practice behaviours.

Insufficient information to support the effectiveness of print-based educational materials compared to other interventions. Print materials may have a beneficial effect on process outcomes compared to no intervention, but not on clinical practice outcomes.

Internet-based CME can produce objectively measured changes in behaviour as well as sustained gains in knowledge that are comparable or superior to those realized from an effective, live, group-based activity. The Internet-based intervention was associated with a significant increase in the percentage of high-risk patients treated with pharmacotherapeutics according to guidelines compared to the live, group-based control

group.

An e-learning course in EBM was as effective in improving knowledge as a standard lecture-based course. There was no statistically significant difference in knowledge of participants in the e-learning course

compared to the lecture-based course. The benefits of an e-learning approach include standardization of teaching materials and it is a potential cost-effective alternative to standard, lecture-based teaching.

The computer-based group significantly outperformed the instructor-led group on the knowledge sub-test at post-test (gain of 28\% vs $26 \%$ ). Participants reported linked, 
Table 6 Summary of articles focused on media used to deliver instruction (Continued)

iuchi $S$ et al. 2009

compared web-based to live instruction

$n=93 ; C=45$, web-based;

$\mathrm{I}=48$, live

Country: Japan

Kemper K et al. 2006

National randomized $2 \times 2$ factorial tria

Health professionals

$\mathrm{n}=1,267$; completion rate $=62 \%$ Group 1 = 318; Group 2 = 318;

Group 3 = 318; Group 4 = 313

Country: USA

RCT to compare the effectiveness of mobile, POC support vs print-based job aids

th year medical students

$\mathrm{n}=169 ; \mathrm{I}=54 ; \mathrm{C} /$ pocket card $=55 ;$ C/nothing $=55$

Country: China

Cluster randomized trial to determine the effectiveness of locally adapted practice guidelines and education about paediatric asthma management delivered to general practitioners using interactive, small group workshops

General practitioners

$n=29$, randomly assigned; $\mid=18$, Technique: interactive vs reading

live, interactive plus guidelines:

C/guidelines only $=18$

$\mathrm{C} /$ nothing $=15$

Country: Australia

Systematic review: 18 studies reviewed Health professionals

to determine outcomes of live,

classroom-based, multi-professional

team training
Frequency: single

ntervention group received live, interactive sessions plus guidelines; control groups

received guidelines only and no intervention.

Media: live

Media: Internet vs live

intervention group received web-based

instruction: control group received didactic

ve instruction.

reminders weekly for 10 weeks (drip-pull):

(boup 3. 40 modules delivered within 4 days

by email (bolus-push); and Group 4: 40

(n) Internet with one

email informing participants of availability

Media: mobile vs print

Technique: POC

Frequency: single

ntervention group given PDA devices with clinical decision support tools; one control group was given a pocket card containing guidelines and the other control group received no intervention.

Media: live vs print only

Technique: multiple

Frequency: single
No significant differences in knowledge were observed between the web-based and face-to-face group. However, the web-based instruction was rated as more flexible and affordable and had a lower drop-out rate than the face-to-face programme.

There were statistically significant improvements in knowledge, confidence and communication scores after the course for each of the Internet-based delivery methods, with no significant differences in any of the three outcomes by delivery strategy. Outcomes were better for those who paid for continuing education credit.

showed improvements in scores for personal application and current use of EBM. The PDA group showed slightly higher scores in all five outcomes, whereas those for the pocket card group were not appreciably different from the previous rotation.

Using interactive small group workshops to disseminate locally adapted guidelines was associated with improvement in general practitioners' knowledge and confidence to manage asthma compared to receiving guidelines alone in the control arm, but did not change their self-reported provision of written action plans.

Although most studies had weak design methods, findings from the 18 studies concluded that team-based training led to positive participant evaluation, knowledge gain and behaviour change. However, the impact on clinical outcomes was limited. 
Table 6 Summary of articles focused on media used to deliver instruction (Continued)

\begin{tabular}{|c|c|c|c|c|}
\hline Sulaiman N et al. 2010 & $\begin{array}{l}\text { Same study design as Liaw S et al. } 2008 \\
\text { for CPE intervention, but used } \\
\text { questionnaires to determine any impact } \\
\text { on completing written action plans or } \\
\text { patient outcomes }\end{array}$ & $\begin{array}{l}411 \text { patient surveys from } \\
\text { patients of three arms utilized } \\
\text { in Liaw, S., et al. } 2008 \text { at baseline; } \\
341 \text { at follow-up } \\
\text { Country: Australia }\end{array}$ & See Liaw S et al. 2008 & $\begin{array}{l}\text { The interactive, small group workshops failed } \\
\text { to translate into increased ownership of } \\
\text { written action plans, improved control of } \\
\text { asthma or improved quality of life, compared } \\
\text { to receiving guidelines alone or control } \\
\text { intervention. }\end{array}$ \\
\hline Triola M et al. 2006 & $\begin{array}{l}\text { RCT to compare effectiveness of virtual } \\
\text { patients to live, standardized patients } \\
\text { for improving clinical skills and } \\
\text { knowledge }\end{array}$ & $\begin{array}{l}\text { I }=23, C=32 \\
\text { Country: USA }\end{array}$ & $\begin{array}{l}\text { Frequency: single } \\
\text { Intervention group received two live, } \\
\text { standardized patient cases and two virtual } \\
\text { patient cases; control group received four } \\
\text { standardized patient cases. }\end{array}$ & $\begin{array}{l}\text { Improvements in diagnostic abilities were } \\
\text { equivalent in groups who experienced cases } \\
\text { either live or virtually. There was no subjective } \\
\text { difference perceived by learners. Using virtual } \\
\text { cases has the potential for cost efficiencies. }\end{array}$ \\
\hline Turner M et al. 2006 & $\begin{array}{l}\text { Randomized, controlled, crossover trial } \\
\text { to compare efficacy, student } \\
\text { preference and cost of web-based, } \\
\text { virtual patient vs live, standardized } \\
\text { patient }\end{array}$ & $\begin{array}{l}\text { 2nd year medical students } \\
\text { I }=25, C=24 \\
\text { Country: USA }\end{array}$ & $\begin{array}{l}\text { Intervention group received web-based } \\
\text { instruction for one topic, then standardized } \\
\text { patient for another topic. This was reversed } \\
\text { for the second cohort, or control group, } \\
\text { standardized patient first followed by } \\
\text { web-based instruction. }\end{array}$ & $\begin{array}{l}\text { There was no statistical difference in learning } \\
\text { outcomes between the web-based and } \\
\text { standardized patient; however, students } \\
\text { preferred the standardized patient format. } \\
\text { Start-up costs were comparable, but the } \\
\text { ongoing costs of the web-based format were } \\
\text { less expensive, suggesting that web-based } \\
\text { teaching may be a viable strategy. }\end{array}$ \\
\hline Wutoh R et al. 2004 & $\begin{array}{l}\text { Systematic review: } 16 \text { articles reviewed } \\
\text { to determine the effect of } \\
\text { Internet-based CME interventions on } \\
\text { physician performance and health } \\
\text { care outcomes }\end{array}$ & Physicians & $\begin{array}{l}\text { Media: Internet } \\
\text { Technique: multiple } \\
\text { Frequency: both single and multiple }\end{array}$ & $\begin{array}{l}\text { Results demonstrate that Internet-based CME } \\
\text { are just as effective in imparting knowledge } \\
\text { as traditional formats of CME. However, there } \\
\text { is a lack of quality studies to conclude } \\
\text { significant positive changes in practice } \\
\text { behaviour and additional studies are needed. }\end{array}$ \\
\hline You J et al. 2009 & $\begin{array}{l}\text { Prospective, randomized study to } \\
\text { investigate usefulness of video via } \\
\text { mobile device as an instruction tool }\end{array}$ & $\begin{array}{l}\text { Surgical residents } \\
I=24, C=25 \\
\text { Country: South Korea }\end{array}$ & $\begin{array}{l}\text { Media: mobile videoconferencing/feedback } \\
\text { Technique: live, interactive with and without } \\
\text { mobile POC feedback using video } \\
\text { Frequency: single } \\
\text { Both intervention groups had a didactic } \\
\text { session, performed a thoracentesis on a } \\
\text { manikin while using video on a mobile phone } \\
\text { and received feedback from a live instructor; } \\
\text { control group did not receive any } \\
\text { video-aided guidance. }\end{array}$ & $\begin{array}{l}\text { The overall success rate for performing needle } \\
\text { thoracocentesis was significantly higher for } \\
\text { the mobile phone video intervention } \\
\text { compared to the control group without aided } \\
\text { instruction. Participants also rated the mobile } \\
\text { phone intervention with significantly higher } \\
\text { scores for instrument difficulty and procedure } \\
\text { satisfaction. }\end{array}$ \\
\hline
\end{tabular}


Table 7 Summary of articles focused on outcomes: knowledge, attitudes, types of skills, practice behaviour, clinical practice outcomes

\begin{tabular}{|c|c|c|c|c|}
\hline Citation & Study design & Participants & Intervention & Key findings \\
\hline \multirow[t]{4}{*}{ Alvarez M and Agra Y 2006} & \multirow{4}{*}{$\begin{array}{l}\text { Systematic review: } 18 \text { articles reviewed to } \\
\text { determine educational interventions in } \\
\text { palliative care and their impact on } \\
\text { practice behaviours }\end{array}$} & \multirow{4}{*}{$\begin{array}{l}\text { Physicians and other allied } \\
\text { health professionals }\end{array}$} & Practice behaviours & \multirow{4}{*}{$\begin{array}{l}\text { Due to a lack of quality studies, there are } \\
\text { insufficient data to conclude about the impact } \\
\text { of palliative care interventions on primary care } \\
\text { physician practice performance. Although } \\
\text { improvements in knowledge, some attitudes } \\
\text { and provider satisfaction were demonstrated, } \\
\text { there were no significant effects reported on } \\
\text { practice behaviours. Didactic education alone } \\
\text { was found to be ineffective. Interventions } \\
\text { involving multiple techniques, reminders and } \\
\text { feedback were found to be more effective at } \\
\text { changing behaviours. }\end{array}$} \\
\hline & & & Technique: multiple & \\
\hline & & & Media: live & \\
\hline & & & $\begin{array}{l}\text { Frequency: both single } \\
\text { and multiple }\end{array}$ & \\
\hline \multirow[t]{4}{*}{ Berkhof M et al. 2010} & \multirow{4}{*}{$\begin{array}{l}\text { Systematic review: } 12 \text { systematic reviews } \\
\text { reviewed to determine effective } \\
\text { educational techniques to teach } \\
\text { communication to physicians }\end{array}$} & \multirow[t]{4}{*}{ Physicians } & Communication skills & \multirow{4}{*}{$\begin{array}{l}\text { Sufficient evidence from } 12 \text { systematic reviews } \\
\text { to recommend training programmes last at } \\
\text { least } 1 \text { day, are learner-centred and focus on } \\
\text { practicing skills. The best training strategies } \\
\text { within the programmes included role-play, } \\
\text { feedback and small group discussions. Training } \\
\text { programmes should include active, } \\
\text { practice-oriented strategies. Oral presentations } \\
\text { on communication skills, modeling and written } \\
\text { information should only be used as supportive } \\
\text { strategies. }\end{array}$} \\
\hline & & & Technique: multiple & \\
\hline & & & Media: multiple & \\
\hline & & & $\begin{array}{l}\text { Frequency: both single } \\
\text { and multiple }\end{array}$ & \\
\hline \multirow[t]{4}{*}{ Bloom B 2005} & \multirow{4}{*}{$\begin{array}{l}\text { Systematic review: } 26 \text { articles (all systemic } \\
\text { reviews or meta-analyses) reviewed to } \\
\text { examine effectiveness of current CME } \\
\text { tools and techniques in changing } \\
\text { physician clinical practices and } \\
\text { improving patient health outcomes }\end{array}$} & \multirow[t]{4}{*}{ Physicians } & $\begin{array}{l}\text { Practice behaviours and } \\
\text { clinical practice outcomes }\end{array}$ & \multirow{4}{*}{$\begin{array}{l}\text { Sufficient evidence to conclude that interactive } \\
\text { techniques (audit/feedback, academic detailing/ } \\
\text { outreach, reminders) are the most effective } \\
\text { CME methods impacting practice outcomes } \\
\text { and behaviours, while clinical guidelines and } \\
\text { opinion leaders are less effective. Didactic } \\
\text { presentations and distributing printed } \\
\text { information had little to no effect on physician } \\
\text { practice. }\end{array}$} \\
\hline & & & Technique: multiple & \\
\hline & & & Media: multiple & \\
\hline & & & $\begin{array}{l}\text { Frequency: both single } \\
\text { and multiple }\end{array}$ & \\
\hline \multirow[t]{4}{*}{ Bordage G et al. $2009^{a}$} & \multirow{4}{*}{$\begin{array}{l}\text { Systematic review: } 29 \text { articles reviewed to } \\
\text { determine if CME leads to an increase in } \\
\text { physician knowledge }\end{array}$} & \multirow[t]{4}{*}{ Physicians and health professionals } & Knowledge & \multirow{4}{*}{$\begin{array}{l}\text { Despite low quality of evidence presented in } \\
\text { the literature, there is sufficient evidence to } \\
\text { confirm an increase in physician knowledge } \\
\text { with the use of multimedia, multiple } \\
\text { instructional techniques and multiple } \\
\text { exposures in CME. }\end{array}$} \\
\hline & & & Technique: multiple & \\
\hline & & & Media: multiple & \\
\hline & & & $\begin{array}{l}\text { Frequency: both single } \\
\text { and multiple }\end{array}$ & \\
\hline \multirow[t]{4}{*}{ Davis D and Galbraith R $2009^{a}$} & \multirow{4}{*}{$\begin{array}{l}\text { Systematic review: } 105 \text { studies reviewed } \\
\text { to determine impact of CME on practice } \\
\text { behaviours }\end{array}$} & \multirow[t]{4}{*}{ Health professionals } & Practice behaviours & \multirow{4}{*}{$\begin{array}{l}\text { Sufficient evidence to support the use of single, } \\
\text { live or multimedia and multiple educational } \\
\text { techniques as effective CME methods in changing } \\
\text { physician performance. Recommend multiple } \\
\text { exposures over single exposures. }\end{array}$} \\
\hline & & & Technique: multiple & \\
\hline & & & Media: live & \\
\hline & & & Frequency: both single & \\
\hline
\end{tabular}


Table 7 Summary of articles focused on outcomes: knowledge, attitudes, types of skills, practice behaviour, clinical practice outcomes (Continued)

\section{Forsetlund L et al. 2009}

Gysels M et al. 2005

Hamilton R 2005

Marinopoulos S et al. $2007^{\mathrm{a}}$

Systematic review: from 68,000 citations, 136 studies and nine systematic reviews were identified and reviewed

Systematic review: 16 articles reviewed to evaluate effective educational techniques for teaching communication skills

Systematic review: 24 articles reviewed to determine how to enhance retention of knowledge and skills during and after resuscitation training

Health professionals

Health professionals health professionals Communication skills

Technique: multiple

Media: multiple

Frequency: both single and multiple

Knowledge, skills

Technique: multiple

Media: multiple

Frequency: both single and multiple

Health professionals and allied

nowledge, skills, practice behaviours and clinical practice outcomes

Technique: multiple

Media: live

Frequency: both single and multiple

Knowledge, skills, practice

studies reviewed to determine the impact of CME on outcomes behaviours and clinical practice outcomes

Mostly physicians

Technique: multiple

Media: live

Frequency: both single and multiple
Sufficient evidence to conclude that educational meetings alone or combined with other

interventions can have a small improvement on professional practice and health care outcomes, but no effect on changing complex behaviours. Previous reviews found that interactive workshops resulted in moderate improvements, whereas didactic sessions did not.

Sufficient evidence to recommend

communication training programmes that are learner-centred, carried out over a long period of time, and combine didactic theoretical components with practical rehearsal and constructive feedback.

Sufficient evidence to recommend in-hospita simulation to teach resuscitation training for nurses in clinical areas in addition to remedial training and the availability of resuscitation equipment for self-study. Video self-instruction has been shown to improve competence in resuscitation.

Firm conclusions are not possible due to the overall low quality of the literature. Despite this, the literature supported the concept that CME was effective at the acquisition and retention of knowledge, attitudes, skills, behaviours and clinical outcomes. Common themes included that live media was more effective than print, multimedia was more effective than single media interventions, multiple exposures were more effective than a single exposure, and simulation methods are effective in the dissemination of psychomotor and procedural skills.

Sufficient information to conclude that the impact of CME on physician performance and patient outcome is small, but has a medium effect on knowledge and a larger effect when the interventions are interactive, use multiple methods and are designed for a small group of physicians from a single discipline. 
Table 7 Summary of articles focused on outcomes: knowledge, attitudes, types of skills, practice behaviour, clinical practice outcomes (Continued)

\begin{tabular}{lll}
\hline Mazmanian P et al. $2009^{\text {a }}$ & $\begin{array}{l}\text { Systematic review: } 37 \text { articles reviewed to } \\
\text { determine the impact of CME on clinical }\end{array}$ \\
nurses, allied health professionals
\end{tabular} practice outcomes

Moores L et al. $2009^{a}$

O'Neil K et al. $2009^{a}$

Rampatige $\mathrm{R}$ et al. 2009

Raza A et al. 2009 (follow-up study to Coomarasamy A and Khan KS 2004)
Systematic review: 136 articles and nine systematic reviews were reviewed to evaluate what makes CME effective

Systematic review: 81 articles retrieved to summarize the best evidence related to use of simulation for learning

Systematic review: from the 136 studies identified in the systematic review, 15 articles, 12 addressing physician application of knowledge and three addressing psychomotor skills, were identified and reviewed

Systematic review: 476 articles selected for inclusion. Section A relates to CPE in general (sections B and C are not relevant); nine studies were reviewed to determine effect of CME on practice behaviours and clinical practice outcomes

Systematic review: Cochrane review of 36 studies reviewed to determine evidence to support effective CME
Health professionals

Technique: multiple

Media: multiple and multiple

Psychomotor skills

Technique: multiple

Media: multiple

Frequency: both single

and multiple

Health professionals and allied health professionals

Health professionals

Health professionals

Media: multiple

Frequency: both single and multiple

Technique: multiple

Media: multiple

Frequency: both single and multiple

General
Frequency: both single ce, there is no firm conclusion on the impact of CME on clinica practice outcomes; however, multimedia, multiple techniques of instruction and multiple exposures to content are suggested to meet instructional objectives intended to improve clinical outcomes.

Significant evidence to support the use of CME interventions that use multimedia in

instruction, multiple instruction techniques and frequency of exposure, to have a positive effect on knowledge, psychomotor skills, practice performance and clinical outcomes. The use of print media alone is not recommended.

Sufficient evidence is available to conclude that use of simulation leads to improved knowledge and skill. Studies with low-quality evidence suggest a transfer of skills to the clinical setting. Instructional design and educational theory, Instructional design and educational theory,
contextualization, transferability, accessibility and contextualization, transferability, accessibility and
scalability must all be considered in simulationbased education programmes.

Knowledge, psychomotor skills Sufficient evidence to support CME as effective Technique: multiple in improving physician application of

knowledge. Multiple exposures and longer durations of CME are recommended to optimize educational outcomes. Quality of evidence does not address to psychomotor skill development

Practice behaviours and clinical practice outcomes

Technique: multiple

Media: multiple

Frequency: both single and multiple
Interactive and practice enabling strategies are more useful than print-based and educational meetings. Multiple education efforts combined with good feedback/interaction between educators and learners are most effective. Opinion leaders and outreach visits shown to be effective.

Evidence from 16 randomized trials support interactive and clinically integrated learning sessions and interactive classroom teaching as second choice for an effective form of CME. Review demonstrated that interactive

workshops improved knowledge and practice behaviours. 
Table 7 Summary of articles focused on outcomes: knowledge, attitudes, types of skills, practice behaviour, clinical practice outcomes (Continued)

\begin{tabular}{|c|c|c|c|c|}
\hline \multirow[t]{4}{*}{ Satterlee W et al. 2008} & \multirow{4}{*}{$\begin{array}{l}\text { Systematic review: nine articles reviewed } \\
\text { to determine impact of CME on clinical } \\
\text { practice outcomes }\end{array}$} & \multirow[t]{4}{*}{ Health professionals } & Clinical practice outcomes & \multirow{4}{*}{$\begin{array}{l}\text { Combined didactic presentations and } \\
\text { interactive workshops and combined didactic } \\
\text { presentations were more effective than } \\
\text { traditional didactic presentations alone. The use } \\
\text { of multiple interventions over an extended } \\
\text { period increased effectiveness. Targeted } \\
\text { education should focus on changing a } \\
\text { behaviour that is simple, since effect size is } \\
\text { inversely proportional to the complexity of the } \\
\text { behaviour. }\end{array}$} \\
\hline & & & Technique: multiple & \\
\hline & & & Media: multiple & \\
\hline & & & $\begin{array}{l}\text { Frequency: both single } \\
\text { and multiple }\end{array}$ & \\
\hline \multirow[t]{4}{*}{ Thomson O'Brien MA et al. 2001} & \multirow{4}{*}{$\begin{array}{l}\text { Systematic review: } 32 \text { articles reviewed to } \\
\text { determine the effect of educational } \\
\text { meetings on practice behaviours and } \\
\text { clinical practice outcomes }\end{array}$} & Health professionals & $\begin{array}{l}\text { Practice behaviours } \\
\text { and clinical } \\
\text { practice outcomes }\end{array}$ & \multirow{4}{*}{$\begin{array}{l}\text { Moderate data quality suggests interactive } \\
\text { workshops can result in moderately large } \\
\text { changes in professional practice. Didactic } \\
\text { sessions alone are unlikely to change } \\
\text { professional practice. }\end{array}$} \\
\hline & & \multirow[t]{3}{*}{$n=2,995$} & Technique: multiple & \\
\hline & & & Media: live & \\
\hline & & & Frequency: single & \\
\hline \multirow[t]{4}{*}{ Williams J et al. 2008} & \multirow{4}{*}{$\begin{array}{l}\text { Systematic review: nine studies reviewed } \\
\text { to evaluate if disaster training improves } \\
\text { knowledge and skills }\end{array}$} & \multirow{4}{*}{$\begin{array}{l}\text { Health professionals and allied } \\
\text { health professionals }\end{array}$} & Knowledge, skills & \multirow{4}{*}{$\begin{array}{l}\text { Insufficient data quality exists to report on the } \\
\text { impact of disaster response training } \\
\text { interventions on knowledge and skills. Data } \\
\text { suggest that both computer-based and live } \\
\text { instruction may increase knowledge. }\end{array}$} \\
\hline & & & Technique: multiple & \\
\hline & & & Media: multiple & \\
\hline & & & $\begin{array}{l}\text { Frequency: both single } \\
\text { and multiple }\end{array}$ & \\
\hline
\end{tabular}

aJHU EPC systematic review. CME Continuing medical education, JHU EPC Johns Hopkins University Evidence-Based Practice Center. 
live instruction for addressing knowledge, while multiple repetitive exposures leads to better knowledge gains than a single exposure. Games can also contribute to knowledge if designed as interactive learning experiences that stimulate higher thinking through analysis, synthesis or evaluation.

No studies or systematic reviews looked only at attitudes, but CPE that includes clinical integration, simulations and feedback may help address attitudes. The JHU EPC group systematic review evaluation of the short- and long-term effects of CPE on physician attitudes reviewed 26 studies and, despite the heterogeneity of the studies, identified trends supporting the use of multimedia and multiple exposures for addressing attitudes [6].

Several systematic reviews looked specifically at skills, concluding that there is weak but sufficient evidence to suggest that psychomotor skills can be addressed with CPE interventions that include simulations, practice with feedback and/or clinical integration. 'Dose-response' or providing sufficient practice and feedback was identified as important for skill-related outcomes. Other RCTs suggest clinically integrated education for supporting skill development. Choa et al. found that neither the audio mentoring via mobile nor animated graphics via mobile resulted in the desired psychomotor skills, reinforcing the need for practice and feedback for psychomotor skill development identified in other studies [49].

Two systematic reviews focused on communication skills and found techniques that include behaviour modeling, practice and feedback, longer duration or more practice opportunities were more effective [52,53]. Evidence suggests that development of communication skills requires interactive techniques that include practice-oriented strategies and feedback, and limit lecture and print-based materials to supportive strategies only.

Findings also suggest that simulation, PBL, multiple exposures and clinically integrated CPE can improve critical thinking skills. Mobile-based POC support was found to be more useful in the development of critical thinking than print-based job aids.

Several systematic reviews specifically looked at CPE, practice behaviours and the behaviours of the provider. These studies found, despite reportedly weak evidence, that interactive techniques that involved feedback, interaction with the educator, longer durations, multiple exposures, multimedia, multiple techniques and reminders may influence practice behaviours.

A targeted review of 37 articles from the JHU EPC review on the impact of CPE on clinical practice outcomes drew no firm conclusions, but multiple exposures, multimedia and multiple techniques were recommended to improve potential outcomes [6]. Interaction and feedback were found to be more useful than print or educational meetings (systematic review of nine articles) [24], but print-based unsolicited materials were not found to be effective [50].
The systematic review of live, classroom-based, multiprofessional training conducted by Rabal et al. found 'the impact on clinical outcomes is limited' [54].

\section{Discussion}

The heterogeneity of study designs included in this review limits the interpretations that can be drawn. However, there is remarkable similarity between the information from studies included in this review and similar discussions published in the educational psychology literature. We believe that there is sufficient evidence to support efforts to implement and evaluate the combinations of training techniques, frequency, settings and media included in this discussion.

Avoid educational techniques that provide a passive transfer of information, such as lecture and reading, and select techniques that engage the learner in mental processing, for example, case studies, simulation and other interactive strategies. This recommendation is reinforced in educational psychology literature [55]. There is sufficient evidence to endorse the use of simulation as a preferred educational technique, notably for psychomotor, communication or critical thinking skills. Given the lack of evidence for didactic methods, selecting interactive, effective educational techniques remains the critical point to consider when designing CPE interventions.

Self-directed learning was also found to be an effective strategy, but requires the use of interactive techniques that engage the learner. Self-directed learning has the additional advantage of allowing learners to study at their own pace, select times convenient for them and tailor learning to their specific needs.

Limited evidence was found to support team-based learning or the provision of training in work teams. There is a need for further study in this area, given the value of engaging teams that are in the same place at the same time in an in-service training intervention. This finding is especially relevant for emergency skills that require the collaboration and cooperation of a team.

Repetitive exposure is supported in the literature. When possible, replace single-event frequency with targeted, repetitive training that provides reinforcement of important messages, opportunities to practice skills and mechanisms for fostering interaction. Recommendations drawn from the educational psychology literature that address the issue of cognitive overload [56] suggest targeting information to essentials and repetition.

Select the setting based on its ability to deliver effective educational techniques, be similar to the work environment and allow for practice and feedback. In this time of crisis, workplace learning that reduces absenteeism and supports individualized learning is critical. Conclusions from literature in educational psychology reinforce the importance of 'situating' learning to make the experience as similar to the workplace as possible [57]. 
Certain common themes emerged from the many articles that commented on the role of media in CPE effectiveness. A number of systematic reviews suggest the use of multimedia in CPE. It is important to note that the studies that found similar knowledge outcomes between computerbased and live instruction stated that both utilized interactive techniques, possibly indicating the effectiveness was due to the technique rather than the media through which it was delivered. While the data on use of mobile technology to deliver CPE were limited, the study by Zurovac et al. indicated the potential power of mobile technology to improve provider adherence to clinical protocols [29]. Currently, there is unprecedented access to basic mobile technology and increasing access to lower-cost tablets and computers. The use of these devices to deliver effective techniques warrants exploration and evaluation, particularly in low- and middle-income countries.

CPE can positively impact desired learning outcomes if effective techniques are used. There are, however, very limited and weak data that directly link CPE to improved clinical practice outcomes. There are also limited data that link CPE to improved clinical practice behaviours, which may influence the strength of the linkage to outcomes.

\section{Limitations}

The following limitations apply to the methodology that we selected for this study. An integrative review of the literature was selected because the majority of published studies of education and training in low- and middleresource countries did not meet the parameters required of a more rigorous systematic review or meta-analysis. The major limitation of integrative reviews is the potential for bias from their inclusion of non-peer-reviewed information or lower-quality studies. The inclusion of articles representing a range of rigor in their research design restricts the degree of confidence that can be placed on interpretations drawn by the authors of those articles, with the exception of original articles that explicitly discussed quality (such as systematic reviews). This review did not make an additional attempt to reanalyse or combine primary data.

Therefore, for purpose of this article, we also graded all articles and included only tier 1 articles in the analysis. This resulted in restriction of information on certain topics for this report, although a wider range of information is available.

We faced an additional limitation in that many articles included in the review were neither fully transparent nor consistent with terminology definitions used in other reports. This is due in part to the fact that we went beyond the bio-medical literature, to include studies conducted in the education and educational psychology literature, as was appropriate to the integrative review methodology. Certain topics were underdeveloped in the literature, which limits the interpretation that can be drawn on these topics. Other topics are addressed in studies conducted using lower-tier research methodologies (for example observational and/or qualitative studies) that were not included in this article. In addition, the overwhelming majority of studies focused on health professionals in developed or middle-income countries. There were very few articles of sufficient rigor conducted in low- and middle-income countries. This limits what we can say regarding the application of these findings among health workers of a lower educational level and in lower-resourced communities.

\section{Conclusions}

In-service training has been and will remain a significant investment in developing and maintaining essential competencies required for optimal public health in all global service settings. Regrettably, in spite of major investments, we have limited evidence about the effectiveness of the techniques commonly applied across countries, regardless of level of resource.

Nevertheless, all in-service training, wherever delivered, must be evidence-based. As stated in Bloom's systematic review, 'Didactic techniques and providing printed materials alone clustered in the range of no to low effects, whereas all interactive programmes exhibited mostly moderate to high beneficial effect. ... The most commonly used techniques, thus, generally were found to have the least benefit' [14]. The profusion of mobile technology and increased access to technology present an opportunity to deliver in-service training in many new ways. Given current gaps in high-quality evidence from low- and middleincome countries, the future educational research agenda must include well-constructed evaluations of effective, cost-effective and culturally appropriate combinations of technique, setting, frequency and media, developed for and tested among all levels of health workers in low- and middle-income countries.

\section{Abbreviations}

BEME: Best Evidence in Medical Education; Cl: Confidence interval; CINAHL: Cumulative Index to Nursing and Allied Health Literature; CME: Continuing medical education; CPE: Continuing professional education; CPR: Cardiopulmonary resuscitation; EBM: Evidence-based medicine; JHU EPC: Johns Hopkins University Evidence-Based Practice Center; MeSH: Medical subject headings; OCEMB: Oxford Centre for Evidence-Based Medicine; PBL: Problem-based learning; POC: Point-of-care; RCT: Randomized controlled trial.

\section{Competing interests}

The authors declare they have no competing interests.

\section{Authors' contributions}

JB performed article reviews for inclusion, synthesized data and served as primary author of the analysis and manuscript. PJ conceived the study, participated in its design and coordination, and provided significant input into the manuscript. JF provided guidance on the literature review process, grading and categorizing criteria, and quality review of selected articles, and participated actively as an author of the manuscript. CC and JBT contributed to writing of the manuscript. JA searched the literature, performed initial 
review and coding, and contributed to selected sections of the manuscript. All authors read and approved the final manuscript.

\section{Acknowledgments \\ We thank the Jhpiego Corporation for support for this research. We thank Dana Lewison, Alisha Horowitz, Rachel Rivas D'Agostino and Trudy Conley for their support in editing and formatting the manuscript. We also thank Spyridon S Marinopoulos, MD, MBA, from the Johns Hopkins University School of Medicine, for his initial input into the study and links to relevant resources. The findings, interpretations and conclusions expressed in this paper are those of the authors and not necessarily those of the Jhpiego Corporation.}

\section{Author details}

'Jhpiego Corporation, 1615 Thames Street, Baltimore, MD 21231, USA. ${ }^{2}$ Independent Consultant, San Diego, CA, USA. ${ }^{3}$ Research Assistant, Baltimore, MD, USA.

Received: 8 August 2012 Accepted: 2 May 2013

Published: 1 October 2013

\section{References}

1. Frenk J, Chen L, Bhutta ZA, Cohen J, Crisp N, Evans T, Fineberg H, Garcia P, Ke Y, Kelley P, Kistnasamy B, Meleis A, Naylor D, Pablos-Mendez A, Reddy S, Scrimshaw S, Sepulveda J, Serwadda D, Zurayk H: Health professionals for a new century: transforming education to strengthen health systems in an interdependent world. Lancet 2010, 376(9756):1923-1958.

2. Wittemore R, Kanfl K: The integrative review: updated methodology. In J Adv Nursing 2005, 52(5):546-553.

3. Marinopoulos SS, Baumann MH: American College of Chest Physicians Health and Science Policy Committee: Methods and definition of terms: effectiveness of continuing medical education: American College of Chest Physicians Evidence-Based Educational Guidelines. Chest 2009, 135(3 Suppl):17S-28S.

4. Oxford Centre for Evidence-Based Medicine (OCEBM) Levels of Evidence Working Group: The Oxford 2011 Levels of Evidence. Oxford: Centre for Evidence Based Medicine; 2011. http://www.cebm.net/?O=1025.

5. Best Evidence in Medical Education (BEME): Appendix 1-BEME Coding Sheet; 2011. http://www.medicalteacher.org/MEDTEACH_wip/supp\%20files/BEME\% 204\%20Figs\%20\&\%20Appendices/BEME4_Appx1.pdf.

6. Marinopoulos SS, Dorman T, Ratanawongsa N, Wilson LM, Ashar BH, Magaziner JL, Miller RG, Thomas PA, Prokopowicz GP, Qayyum R, Bass EB: Effectiveness of continuing medical education. Evidence Report/Technology Assessment, No. 149, (Prepared by the Johns Hopkins Evidence-based Practice Center, under Contract No.290-02-0018) AHRQ Publication No. -7-E006. Agency for Healthcare Research and Quality: Rockville, MD; January 2007.

7. Triola M, Feldman H, Kalet AL, Zabar S, Kachur EK, Gillespie C, Anderson M, Griesser C, Lipkin M: A randomized trial of teaching clinical skills using virtual and live standardized patients. J Gen Intern Med 2006, 21(5):424-429.

8. Smits PB, De Buisonje CD, Verbeek JH, Van Dijk FJ, Metz JC, Ten Cate OJ: Problem-based learning versus lecture-based learning in postgraduate medical education. Scand J Work Environ Health 2003, 29(4):280-287.

9. White M, Michaud G, Pachev G, Lirenman D, Kolenc A, FitzGerald JM: Randomized trial of problem-based versus didactic seminars for disseminating evidence-based guidelines on asthma management to primary care physicians. J ContinEduc Health Prof 2004, 24(4):237-243.

10. De Lorenzo RA, Abbott CA: Effectiveness of an adult-learning, self-directed model compared with traditional lecture-based teaching methods in out-of-hospital training. Acad Emerg Med 2004, 11(1):33-37.

11. Lin CF, Lu MS, Chung CC, Yang CM: A comparison of problem-based learning and conventional teaching in nursing ethics education. Nurs Ethics 2010, 17(3):373-382.

12. Reynolds A, Ayres-de-Campos D, Pereira-Cavaleiro A, Ferreira-Bastos L: Simulation for teaching normal delivery and shoulder dystocia to midwives in training. Educ Health (Abingdon) 2010, 23(3):405.

13. Alvarez MP, Agra Y: Systematic review of educational interventions in palliative care for primary care physicians. Palliat Med 2006, 20(7):673-683.

14. Bloom BS: Effects of continuing medical education on improving physician clinical care and patient health: a review of systematic reviews. Int J Technol Assess Health Care 2005, 21(3):380-385.
15. Satterlee WG, Eggers RG, Grimes DA: Effective medical education: insights from the Cochrane Library. Obstet Gynecol Surv 2008, 63(5):329-333.

16. Herbert CP, Wright JM, Maclure M, Wakefield J, Dormuth C, Brett-MacLean P, Legare J, Premi J: Better Prescribing Project: a randomized controlled trial of the impact of case-based educational modules and personal prescribing feedback on prescribing for hypertension in primary care. Fam Pract 2004, 21(5):575-581.

17. Issenberg SB, McGaghie WC, Petrusa ER, Lee Gordon D, Scalese RJ: Features and uses of high-fidelity medical simulations that lead to effective learning: a BEME systematic review. Med Teach 2005, 27(1):10-28.

18. Raza A, Coomarasamy A, Khan KS: Best evidence continuous medical education. Arch Gynecol Obstet 2009, 280(4):683-687.

19. Akl EA, Pretorius RW, Sackett K, Erdley WS, Bhoopathi PS, Alfarah Z, Schunemann HJ: The effect of educational games on medical students' learning outcomes: a systematic review: BEME Guide No 14. Med Teach 2010, 32(1):16-27.

20. Laprise R, Thivierge R, Gosselin G, Bujas-Bobanovic M, Vandal S, Paquette D, Luneau M, Julien P, Goulet S, Desaulniers J, Maltais P: Improved cardiovascular prevention using best CME practices: a randomized trial. $J$ Contin Educ Health Prof 2009, 29(1):16-31.

21. Forsetlund L, Bjorndal A, Rashidian A, Jamtvedt G, O'Brien MA, Wolf F, Davis D, Odgaard-Jensen J, Oxman AD: Continuing education meetings and workshops: effects on professional practice and health care outcomes. Cochrane Database Syst Rev 2009, 2, CD003030.

22. Mansouri M, Lockyer J: A meta-analysis of continuing medical education effectiveness. J Contin Educ Health Prof 2007, 27(1):6-15.

23. Perry M, Draskovic I, Lucassen $P$, Vernooij-Dassen $M$, Van Achterberg $T$, Rikkert MO: Effects of educational interventions on primary dementia care: A systematic review. Int J Geriatr Psychiatr 2011, 26(1):1-11.

24. Rampatige R, Dunt D, Doyle C, Day S, Van Dort P: The effect of continuing professional education on health care outcomes: lessons for dementia care. Int Psychogeriatr 2009, 21(Suppl 1):S34-S43.

25. Blaya JA, Fraser HS, Holt B: E-health technologies show promise in developing countries. Health Aff (Millwood) 2010, 29(2):244-251.

26. Leung GM, Johnston JM, Tin KY, Wong IO, Ho LM, Lam WW, Lam TH: Randomised controlled trial of clinical decision support tools to improve learning of evidence-based medicine in medical students. BMJ 2003, 327(7423):1,090.

27. You JS, Park S, Chung SP, Park JW: Usefulness of a mobile phone with video telephony in identifying the correct landmark for performing needle thoracocentesis. Emerg Med J 2009, 26(3):177-179.

28. Yuan $H$, Williams BA, Fan $L$ : A systematic review of selected evidence on developing nursing students' critical thinking through problem-based learning. Nurse Educ Today 2008, 28(6):657-663.

29. Zurovac D, Sudoi RK, Akhwale WS, Ndiritu M, Hamer DH, Rowe AK, Snow RW: The effect of mobile phone text-message reminders on Kenyan health workers' adherence to malaria treatment guidelines: a cluster randomised trial. Lancet 2011, 378(9793):795-803.

30. Murad MH, Coto-Yglesias F, Varkey P, Prokop L, Murad AL: The effectiveness of self-directed learning in health professions education: a systematic review. Med Educ 2010, 44(11):1,057-1,068.

31. Young JM, Ward J: Can distance learning improve smoking cessation advice in family practice? A randomized trial. J Contin Educ Health Prof 2002, 22(2):84-93.

32. Harder BN: Use of simulation in teaching and learning in health sciences: a systematic review. J Nurs Educ 2010, 49(1):23-28.

33. McGaghie WC, Siddall VJ, Mazmanian PE, Myers J: American College of Chest Physicians Health and Science Policy Committee: Lessons for continuing medical education from simulation research in undergraduate and graduate medical education: effectiveness of continuing medical education: American College of Chest Physicians Evidence-Based Educational Guidelines. Chest 2009, 135(3 Suppl):62S-68S.

34. Sturm LP, Windsor JA, Cosman PH, Cregan P, Hewett PJ, Maddern GJ: A systematic review of skills transfer after surgical simulation training. Ann Surg 2008, 248(2):166-179.

35. Steadman RH, Coates WC, Huang YM, Matevosian R, Larmon BR, McCullough $L$, Ariel D: Simulation-based training is superior to problem-based learning for the acquisition of critical assessment and management skills. Crit Care Med 2006, 34(1):151-157.

36. Lamb D: Could simulated emergency procedures practised in a static environment improve the clinical performance of a Critical Care Air Support Team (CCAST)? A literature review. Intensive Crit Care Nurs 2007, 23(1):33-42. 
37. Bruppacher HR, Alam SK, LeBlanc VR, Latter D, Naik VN, Savoldelli GL, Mazer $C D$, Kurrek MM, Joo HS: Simulation-based training improves physicians' performance in patient care in high-stakes clinical setting of cardiac surgery. Anesthesiology 2010, 112(4):985-992.

38. Daniels K, Arafeh J, Clark A, Waller S, Druzin M, Chueh J: Prospective randomized trial of simulation versus didactic teaching for obstetrical emergencies. Simul Healthc 2010, 5(1):40-45.

39. Ellis D, Crofts JF, Hunt LP, Read M, Fox R, James M: Hospital, simulation center, and teamwork training for eclampsia management: a randomized controlled trial. Obstet Gynecol 2008, 111(3):723-731.

40. Hamilton R: Nurse's knowledge and skill retention following cardiopulmonary resuscitation training: a review of the literature. J Adv Nurs 2005, 51(3):288-297.

41. Merien AE, Van de Ven J, Mol BW, Houterman S, Oei SG: Multidisciplinary team training in a simulation setting for acute obstetric emergencies: a systematic review. Obstet Gynecol 2010, 115(5):1,021-1,031.

42. Crofts JF, Ellis D, Draycott TJ, Winter C, Hunt LP, Akande VA: Change in knowledge of midwives and obstetricians following obstetric emergency training: a randomised controlled trial of local hospital, simulation centre and teamwork training. BJOG 2007, 114(12):1,534-1,541.

43. Kerfoot BP, Fu Y, Baker H, Connelly D, Ritchey ML, Genega EM: Online spaced education generates transfer and improves long-term retention of diagnostic skills: a randomized controlled trial. J Am Coll Surg 2010, 211(3):331-337.

44. Kerfoot BP, Kearney MC, Connelly D, Ritchey ML: Interactive spaced education to assess and improve knowledge of clinical practice guidelines: a randomized controlled trial. Ann Surg 2009, 249(5):744-749.

45. Kerfoot BP, Baker HE, Koch MO, Connelly D, Joseph DB, Ritchey ML: Randomized, controlled trial of spaced education to urology residents in the United States and Canada. J Urol 2007, 177(4):1,481-1,487.

46. Coomarasamy A, Khan KS: What is the evidence that postgraduate teaching in evidence based medicine changes anything? A systematic review. BMJ 2004, 329(7473):1,017.

47. Harrington SS, Walker BL: The effects of computer-based training on immediate and residual learning of nursing facility staff. J Contin Educ Nurs 2004, 35(4):154-163. quiz 186-7.

48. Curran VR, Fleet $L$ : A review of evaluation outcomes of web-based continuing medical education. Med Educ 2005, 39(6):561-567.

49. Choa M, Park I, Chung HS, Yoo SK, Shim H, Kim S: The effectiveness of cardiopulmonary resuscitation instruction: animation versus dispatcher through a cellular phone. Resuscitation 2008, 77(1):87-94.

50. Farmer AP, Legare F, Turcot L, Grimshaw J, Harvey E, McGowan JL, Wolf F: Printed educational materials: effects on professional practice and health care outcomes. Cochrane Database Syst Rev 2008, 3, CD004398.

51. Liaw ST, Sulaiman ND, Barton CA, Chondros P, Harris CA, Sawyer S, Dharmage SC: An interactive workshop plus locally adapted guidelines can improve general practitioners asthma management and knowledge: a cluster randomised trial in the Australian setting. BMC Fam Pract 2008, 9:22.

52. Gysels M, Richardson A, Higginson IJ: Communication training for health professionals who care for patients with cancer: a systematic review of training methods. Support Care Canc 2005, 13(6):356-366.

53. Berkhof M, Van Rijssen HJ, Schellart AJ, Anema JR, Van der Beek AJ: Effective training strategies for teaching communication skills to physicians: an overview of systematic reviews. Patient Educ Couns 2011, 84(2):152-162.

54. Rabol LI, Ostergaard D, Mogensen T: Outcomes of classroom-based team training interventions for multiprofessional hospital staff: A systematic review. Qual Saf Health Care 2010, 19(6):e27.

55. Woolfolk AE: Educational Psychology. 11th edition. Upper Saddle River, NJ: Pearson/Merrill/Prentice Hall; 2009.

56. Mayer RE: Applying the science of learning to medical education. Med Educ 2010, 44(6):543-549.

57. Gott S, Lesgold A: Competence in the workplace: how cognitive performance models and situated instruction can accelerate skill acquisition. In Advances in Instructional Psychology, Volume 4. Edited by Glaser R. Hillsdale, NJ: Erlbaum; 2000.

doi:10.1186/1478-4491-11-51

Cite this article as: Bluestone et al:: Effective in-service training design and delivery: evidence from an integrative literature review. Human Resources for Health 2013 11:51.

\section{Submit your next manuscript to BioMed Central and take full advantage of:}

- Convenient online submission

- Thorough peer review

- No space constraints or color figure charges

- Immediate publication on acceptance

- Inclusion in PubMed, CAS, Scopus and Google Scholar

- Research which is freely available for redistribution 